\title{
Post-crisis development model of Serbia
}

\begin{abstract}
In the previous decade, a vehicle for the economic growth and development of Serbia was intended to be the simultaneous growth of personal and public spending on the one hand, and the creation of the institutional and substantive preconditions for stable growth by way of market reforms, privatisation and the inflow of foreign investment on the other. The global economic downturn has unveiled the unsustainability of the existing economic development model of growth and development in Serbia, as well as the requirement for radical change if a destiny as an undeveloped and over-indebted country is to be avoided. In a situation when the proceeds of privatisation are diminishing and there is a grim outlook in connection with further excessive foreign borrowing, Serbia must turn to a new pro-investment and export-oriented model for economic growth and development. Thus, in 2011-2020 the dominant growth of spending in the primary scenario of the future development of Serbia must be replaced by a dominant growth of investment.
\end{abstract}

Keywords: development, growth, spending, investment

\section{Introduction}

In view of the results achieved in the 2001-2008 period, it may be concluded that they were, at best, superficial. An average annual real rate of growth in GDP of $5.4 \%$ looks substantial, but it was insufficient to compensate for the huge development gap of the 1990s. Another, bigger, problem was an insufficient structure for the creation and use of the increasing amount of GDP, which led to an increase in the foreign economic imbalance due to the rise of foreign trade and the current payment deficit. The main components of economic growth were services.

As for reform and transition processes, Serbia is only at the half-way stage. Therefore, a new model for economic growth and development in the decade ahead of us requires two, mutually-related turnabouts. The first turnabout is directed from consumers towards a pro-investment and export-oriented pattern of economic growth. The other is necessary in the field of the acceleration of reform processes and European integration, and the establishment of appropriate macro-economic and structural policies. It is about the creation of a more attractive economic atmosphere without which the realisation of a new model for growth and development would not be possible.

A model of the economic growth of Serbia, 2001-2008

In 2000, the Serbian economy found itself with a structure which had been finalised a quarter of a century before, during the second half of the 1970s. The situation in industry was the most difficult. It may be evaluated that industrial equipment had been 
depreciated to about $12 \%-15 \%$ of its real value from 1989 . Structurally, the situation was even more difficult because equipment found on the spot was worn-out, suitable for the market requirements of a quarter of a century previously. Any understanding of the degree of capacity utilisation that may be achieved by the provision of sufficient working capital towards achieving the growth rate was an illusion. It required substantial investment and the creation of a new structure.

During the 1991-2000 period, Serbia lost potential domestic product of over $€ 150 \mathrm{bn}$, or about $€ 20000$ per inhabitant per year. In 2000 , the achieved level of GDP per inhabitant was nearly $€ 1600$, in relation to a potential GDP per capita, which was $€ 4100$.

This led to an enormous drop in the living standards of a huge majority of people. The middle class was almost destroyed while the number of poor people increased rapidly. Serbia did not make progress according to its possibilities; it even regressed. That is why salaries and pensions were low; the situation in the health system was disastrous; young and educated people went abroad looking for a better living; and there was a phenomenon of people surviving by searching through refuse bins. The foreign exchange savings of citizens was simply annulled.

The message of this Introduction and further discussion is, first, that the achieved volume of investment between 2001 and 2008 was not able to compensate for the lagging of investment as a whole; and, second, that the investment structure was wrong. A greater part of the tradable goods sector remained on a level adequate to the technology and the market of more than thirty years previously. The result of this is that the growth model and macro-economic balance up to now is exhausted and can simply no longer function.

When compared with the average growth of the global economy, GDP growth in Serbia was faster, but it is not the case when compared to the growth in some other countries from the region or with total growth in developing countries. An insufficiently dynamic economic growth - especially bearing in mind the lag of the 1990s and the lost potential domestic product in that period - is one of the reasons why Serbia has not created new comparative advantages in international exchange. The other reason is the structure of that growth. Particularly above-average growth rates of gross added value were in: traffic, storage and communications (15.9\% per year); trade $(13.9 \%)$; and financial mediation (5.9\%). From a starting contribution to the formation of GDP of $17.3 \%$ in 2001, these three sectors contributed almost $30 \%$ of GDP in 2008; in other words, they were the main components of economic growth. On the other hand, the sectors in which material goods are being produced had GDP growth far below average: agriculture, with $2.3 \%$ per year; and manufacturing industry with $1 \%$ (total industry $1.2 \%$ ). Somewhat faster, but also below average, production and GDP in the construction industry grew (by about $2 \%$ per a year). Therefore, the participation of these production sectors in total GDP formation, from starting at about $40 \%$ in 2001, had been reduced to about $31 \%$ in 2007 and 2008 (Fund for the Development of Economic Science, 2010).

The basic conclusion regarding our foreign trade imbalance and future economic growth originates from the relationship between growth and the participation of tradable and non-tradable goods in GDP. In 2001, tradable goods (in agriculture and man- 
ufacturing industry) contributed about $32 \%$ to the formation of GDP but, by 2008, that figure had dropped below $24 \%$. In that way, the offer of goods for export was reduced as a structural phenomenon and demand for imported goods increased, independent of internal demand (and consumption within it) growing faster than GDP - which entailed a continuous inflation of the deficit in the current part of the balance of payments. Such a model may be sustained for as long as sufficient foreign capital inflow exists which will, by an appropriate surplus in the financial-capital transaction balance, cover the deficit in current transactions that was being continuously expanded by the growth in the trade deficit.

In sum, the structure of the economic growth that was achieved did not provide the prerequisites for a stable future development.

Growth in domestic demand (7.5\% per year) and consumption $(7.3 \%)$ during the first decade of this century (i.e. up to 2008 inclusive, when the crisis erupted) was significantly faster than the growth in GDP (5.4\% per year) so that, during the last two years (2007 and 2008), the value of domestic demand exceeded the value of gross domestic product by more than $23 \%$. About $19 \%$ of total domestic demand was satisfied by a surplus of imports over exports, i.e. by a deficit in goods and services, which was rising by $10.9 \%$ per year (Foster, 2008).

The essence may also be described as follows: in the ambience of an almost continuous preliminary election situation, the character of public consumption was deformed in such a way that the focus of its action was directed to the establishment of social peace.

Models of the dynamic economic growth of Serbia in the post-crisis period

\section{Basic scenario}

In the basic scenario of future development between 2011 and 2020, the predominance of growth in consumption is replaced by a predominance of growth in investment. The basic scenario for the period up to 2020 assumes the acquisition of the status of EU candidate country, culminating at the end of that time in Serbia becoming a member of the EU, and the deployment of the economic concessions that would be enabled by such a political development. Average annual real GDP growth would be $5.8 \%$ and domestic demand $4.7 \%$. Final domestic demand - due to the reduction in the share of negative net exports, for the purpose of improving the sustainability of foreign debt must grow slower than GDP. The value of GDP in 2020 would attain a level of $€ 52.7 \mathrm{bn}$, or about $€ 7500$ per inhabitant. Within such dynamics, productivity would be increased cumulatively by $50.4 \%$ up to the end of the period in question and employment by $16.9 \%$ (which corresponds to a growth in the number of employees of about 440000 ).

Dynamically, GDP growth is being accelerated over time and is conditioned by investment dynamics. Projected average industry growth of $6.9 \%$ and construction industry growth of $9.7 \%$, and growth in services of $5.5 \%$, create the conditions for a change in the economic structure. The share of tradable products in GDP would be increased from $30.7 \%$ in 2009 to $33.1 \%$ in 2020 , despite a lower average rate of growth in agriculture and a drop in its overall share - from $9.6 \%$ in 2009 to $7.6 \%$ in 2020 . 
The targeted parameters in this basic development scenario are:

- raising the share of fixed investments to $25 \%$ in 2015 and to $28 \%$ in 2020 (with an average annual growth rate of up to $9.7 \%$ )

- a reduction in the share of state consumption in GDP from $25 \%$ in 2009 to $12.4 \%$ in 2020

- a raising in the share of GDP taken by exported goods and services from $27.6 \%$ in 2009 to $65 \%$ in 2020

- a substantial restriction of the deficit in current transactions in the balance of payments from $7.1 \%$ of GDP in 2010 to $3.3 \%$ in 2020 .

Chart 1 - Cumulative growth of GDP, productivity and employment, 2011-2020 (\%)

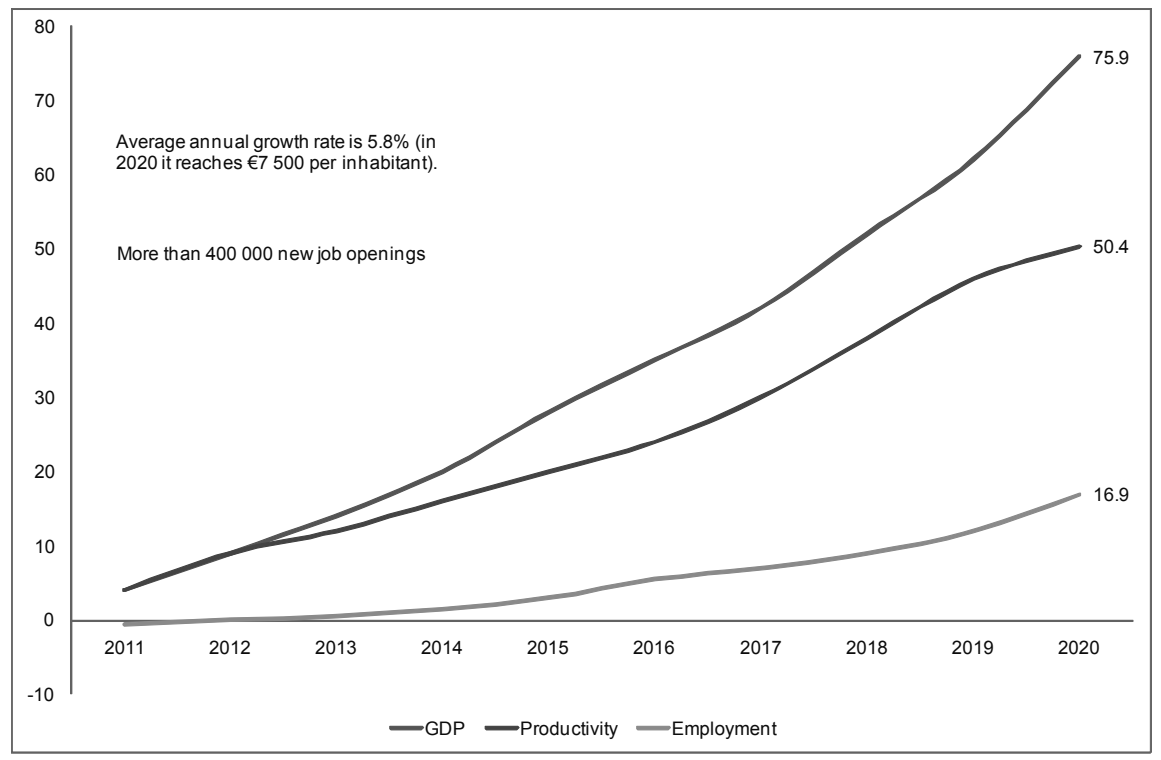

Source: Economic Institute

The targeted share for investment will be achieved on the basis of an average annual real growth rate of $9.7 \%$ (two-thirds faster than GDP growth). The value of those investments would be increased from $€ 4.9 \mathrm{bn}$ in 2009 (estimate) to about $€ 9 \mathrm{bn}$ in 2015 and to almost $€ 15 \mathrm{bn}$ in 2020 . Accordingly, the share of gross domestic savings in gross investments would reach almost $55 \%$ in 2015, from about $14 \%$ in 2009 , and $61 \%$ in 2020.

As for the balance of payments, the main targeted parameters are: a raising in the share of exported goods and services in GDP from $27.6 \%$ in 2009 to $65 \%$ in 2020 ; and a limitation of the reduction of the coverage of the import of goods and services by foreign exchange reserves (from eleven months in 2009 to about six months at the 
end of the period). The intention is that the net inflow from foreign direct investments will be $€ 22.7 \mathrm{bn}$ in the period 2011-2020 (the cumulative amount of deficit from current transactions in that period is about $€ 17 \mathrm{bn}$; probable donations that would mitigate the situation have not been taken into account). On the other hand, the gross inflow of longterm credits over the ten years would be $€ 51.1 \mathrm{bn}$.

The sustainability of the presented development model relies on three groups of prerequisites which are, to a certain extent, mutually inclusive conditions.

Firstly, adjustments to the economic system, macro-economic policy and sectoral policies need to be made towards developing the concept of the acceleration of economic growth based on the replacement of consumption by a pro-investment development scenario and a relocation of the focus of investment towards tradable goods. The reform of the public sector has a specific place in that respect. Deviation from these prerequisites, bearing in mind the forthcoming election cycle, presents one of the risks to achieving the results of such a scenario.

The second group consists of the prerequisites that enable continuity in approximation to the EU and a speeding up of the process of becoming an EU member. When speaking of the economic surroundings of the Serbian economy, this group of prerequisites has another side, too - a period for the recovery of the global economy, on which depends the projected growth in our exports and an economic orientation which relies on export demand.

Thirdly, and perhaps most importantly, is the risk linked with the problem of the sustainability of foreign debt and external solvency. In the next five years, Serbia bears a risk of the burden of high instalments in the payment of private debt and must base its necessary investment cycle on foreign direct investments, public loans and a substantial share of domestic savings in the financing of investments. The main point of risk in the financing of the balance of payments is a high debt servicing rate; this is more or less already predetermined for the first five years and, in 2015, it would still be $38 \%$ to $39 \%$ of the value of the export of goods and services. Hence, we have an imperative to reduce the share of the deficit in trade exchange as well as the share of GDP taken by the deficit in current transactions in the balance of payments.

In this analysis of the basic scenario, we have shown above that the achievement of projected economic growth and sustainability in the balance of payments depend both on achieving the targeted parameters and on the direction of the developing economic policy, under which the essential character of that scenario becomes defined as pro-investment, stabilising or 'social'. Apart from that, the image of the country (or the evaluation of risk) is important, and not only the inflow but also the price of capital depends on it.

The increase in the limit of the level of foreign exchange reserves from six to nine months in relation to imports requires an additional inflow of capital in the period in question of about $€ 10 \mathrm{bn}$, by means of investment. We need to remember here that it is necessary to relax debt with a net outflow within several years in order to avoid a (private) debt crisis and also that it increases the required inflow of net strategic direct investment by about one-half. The increase in the projected interest rate of one per cent requires an additional inflow of about $€ 1 \mathrm{bn}$. 
The alternative to this increase in the inflow of capital, i.e. a saving of this figure of $€ 10 \mathrm{bn}$, requires a strict reduction in the share of the deficit of goods and services in GDP (in this way also a reduction of current transactions in the balance of payments). However, such a reduction would lower consumption growth below an acceptable level. That would - via a reduction of investment growth in favour of consumption - reflect on the further transformation of this pro-investment scenario into a 'social one', with a reduction of projected GDP growth as a final consequence, a strengthening of inflation pressures and a recognition of the need for such a scenario to be transformed into a stabilising one (Fund for the Development of Economic Science, 2010).

\section{Development scenarios}

Out of the possible numerous development scenarios during the next ten years, we would like to mention here just two:

a) a scenario with lower economic growth in relation to the basic one

b) a 'social' scenario, or a 'populist' scenario for economic growth (mentioning only basic outcomes).

\section{Lower economic growth}

In the first case, a small reduction in the average annual real growth rate of GDP (to $4.9 \%$ instead of $5.8 \%$ ) in the period up to 2020 would reduce the number of workplaces by 76000 in relation to the basic growth scenario and productivity would be increased cumulatively by $41 \%$ instead of more than $50 \%$. The possibilities of the growth in consumption would be limited to $2.5 \%$ per year instead of $3.5 \%$, while investment should grow at approximately the same rate as the growth of the share of exports in GDP. Reform efforts would turn out almost the same.

This scenario is based on a projection of an average annual growth in GDP for $2011-2020$ of $4.9 \%$ along with the assumption that the GDP growth rate during the first two years would be within a zone below $4 \%$ per year; that, during the last two years of the first five it would reach $5 \%$; and that average growth for 2011-2015 would be $4.4 \%$ (during the second five years $5.4 \%$ ). This more detailed analysis stems from the assumption that the recovery will be slower given the global economic crisis. Essentially, this scenario does not presuppose the acquisition of EU member status until the end of the period in question and thus minimises the effects of the usage of the economic concessions obtained by such a political development. However, the proinvestment scenario remains, with a structural transformation towards the production of tradable goods.

The result is similar to that contained in the basic sub-type: an increase in the share of tradable goods in GDP from $30.7 \%$ in 2009 to $33.1 \%$ in 2020 . However, when keeping the productivity and employment growth rates from the basic sub-type, the number of new work vacancies would be reduced (by 75 600, which would correspond to an employment growth a bit above 350000 ), while productivity would be increased cumulatively by $41.7 \%$. 
The two main targeted parameters in the balance of payments are the same as in the basic scenario:

- increasing the share of exported goods and services in GDP from $27.6 \%$ in 2009 to $65 \%$ in 2020 (i.e. to above $33 \%$ in $2011 ; 40 \%$ in $2014 ; 43.5 \%$ in 2015 ; and $52 \%$ in 2017; while the share in the remaining years is increased proportionally for each of the two targets)

- a limitation in the reduction of the coverage of the import of goods and services by foreign exchange reserves - it was eleven months in 2009 and is to be reduced gradually (according to the reduction of risk regarding external solvency) to six months at the end of the period in question (but by no means below this level).

However, the derived magnitudes are changed, and so the maximum growth rate of the export of goods and services within the whole period is $14 \%$, and $13 \%$ for imports. Here too, final domestic demand grows more slowly than GDP. Average growth rates for the whole period are:

- GDP: $4.86 \%$

- final domestic demand: $3.75 \%$

- investments: $9.00 \%$

- consumption: $2.56 \%$.

The growth in consumption in 2011 is symbolic ( $0.6 \%)$; during the next two years it does not reach more than $1.5 \%$, in 2014 , and $2 \%$ in 2015 . The average for the whole of the first five years is $1.4 \%$ and only in the second five year period is the environment created, via an acceleration of GDP growth and a slowing down in the expansion of investment, for increasing average consumption growth to the region of $3.5 \%$ to $4 \%$. The assumption is that it would exceed $4 \%$ per year during the last three years. The consumption of the state would be reduced successively up as far as 2016 .

These figures hide the main risk. Will economic policy manage to keep consumption within the limits during the next five years, or will a scenario of repressing investment growth in favour of consumption, given the electoral timetable, transform this scenario into a pro-social one?

Another risk relates to the sustainability of foreign debt. A somewhat lower inflow of net strategic direct investment is projected than in the basic scenario, of $€ 19.3 \mathrm{bn}$. In this scenario, the period of the negative net inflow of long-term credits is extended to six years (2012-2017), with a total surplus in the payment instalments of capital over the inflow of $€ 2.9 \mathrm{bn}$. There is a danger that insufficient space for consumption is compensated for by a softer reduction in the share of the deficit of goods and services in GDP that would intensify the risks regarding the sustainability of foreign debt.

The 'social', or 'populist', scenario

The populist scenario is much more dangerous. A projected low average annual growth rate of $3 \%$ (with decreasing dynamics during the period), combined with an increase in all kinds of consumption, with subsidised employment during the first two years, would lead inevitably to the growth of inflation as well as the depreciation of the dinar. Such a scenario could not be realised in the long-term because of the dramatic reduction in foreign exchange reserves which would occur in 2013, while the servicing 
of foreign debt would take almost one-fifth of the achieved GDP; that is, nearly $60 \%$ of the value of exported goods and services. This scenario is unsustainable. Its real consequence would be a balancing of consumption through high inflation and the strong real depreciation of the dinar, as well as a spontaneous transformation into a stabilising scenario by the first half of the decade in question, with the cancellation of real consumption growth.

We are drawing attention here to the populist scenario, bearing in mind that the stand-by arrangement with the International Monetary Fund will expire in an electoral year, especially in the case that it is decided to move to a scenario of the social type. Consumption and subsidised employment would be supported in the next two years, i.e. in a pro-social scenario, with the following possible outcomes:

- an average growth of GDP in the whole decade of $3 \%$ per a year; the maximum growth rate $(3.8 \%)$ would be achieved in 2014 and, after that, it would be successively reduced year-on-year to realise $2.2 \%$ in 2020 (Fund for the Development of Economic Science, 2010)

- an average growth rate in total industrial production and manufacturing industry of $2.9 \%$ (maximum in the $2012-2014$ period of $3.7 \%$ and, after that, reduced further to $1.7 \%$ in 2020). This is based, first of all, on the more rapid growth of food industry production that does not require huge investment. The share of industrial production in GDP is reduced

- the loss of about 230000 jobs, on the basis of the assumed dimensions of productivity, while the growth of employment and productivity does not raise competition for the purpose of the expansion of exports

- a stabilising of the share of the deficit of goods and services in GDP to a level from 2009 of $15.5 \%$

- average annual growth rates for the period 2011-2020 would be:

- GDP: $3.0 \%$

- domestic final demand: $2.1 \%$

- investments: $3.8 \%$

- consumption: $1.9 \%$.

- a maintenance of the achieved share of investment in GDP in 2011 and, after that, a gradual growth in that share up to $20 \%$ in 2020 , with a growth of $3.7 \%$ to $6 \%$ per year

- an environment established for the growth of consumption of up to (or about) $2 \%$ per year - on average about $2.5 \%$ in the first half of the decade and, after that, a sharp reduction in that growth, reaching stagnation by the end of the period

- a capital gap in terms of financing the balance of payments ('mistakes and omissions') of $€ 13.8 \mathrm{bn}$, with the net inflow of strategic direct investment between 2011 and 2020 remaining at $4 \%$ of GDP. There is a negative balance and the payment instalments of long-term loans in that period would reach $€ 3.5 \mathrm{bn}$

- a potentially serious reduction in the projected inflow of loans to the public sector of $€ 8.5 \mathrm{bn}$, because the conditions for the approval of such loans will not exist. In other words, about $€ 20$ bn are missing

- a level of foreign exchange reserves in the last year, sufficient to cover six months of imports, of about $€ 14.7 \mathrm{bn}$, under the assumption that these are unchanged in the 
2012-2017 period and, after that, grow in order to remain at a level of nearly six months coverage (more precisely, 5.5 months in 2020). In other words, foreign exchange reserves would be wiped out before the expiry of the decade in question by money being spent on an insufficient inflow (probably by 2016). The alternative is to incur debts at a high price and a higher interest rate effect towards an insufficient amount of capital and a resulting 'breakage' in external solvency. Namely, servicing of the debt would engage almost one-fifth of GDP and would exceed one-half of the value of exported goods and services by the end of 2013 .

\section{References}

Foster, B (2008) 'The Financialisation of Capital and the Crisis' Monthly Review.

Jakopin, Edvard (2009) 'The Effects of the Economic Crisis on the Regional Development of Serbia' international academic meeting: Regional Development and Demographic Currents in South-Eastern Europe held in Niš. The School of Economy: Belgrade.

Jakopin, Edvard and Stevan Devetaković (2009) 'Regionalisation in Serbia' academic meeting Transition in Serbia and Global Economic Crisis Society of Scientific Economists: School of Economy, Belgrade.

Korten D. C (2009) Agenda for a New Economy: From Phantom Wealth to Real Wealth Berrett-Kohler Publishers.

Palley T. I (2008) Financialization: What is it and why it matters Macroeconomic Policy Institute Working Paper 04/2008.

Fund for the Development of Economic Science (2010) Post-crisis model of Economic Growth and Development of Serbia 2011-2020 School of Economy, Belgrade.

Republic Institute for Development (2010) Report on the Development of Serbia 2009 Belgrade. 